\title{
Slowly growing mass on the left shoulder
}

\author{
Wayne B. Cohen-Levy ${ }^{1} \cdot$ Jean Jose $^{2,3} \cdot$ Andrew E. Rosenberg ${ }^{2,4} \cdot$ Juan Pretell-Mazzini $^{2,5}$ (D)
}

Published online: 30 August 2017

(C) ISS 2017

History: A 30 year-old otherwise healthy female presented with a slow growing painless mass on her left shoulder that has recently become painful (Figs. 1 and 2).

The diagnosis can be found at doi: https://doi.org/10.1007/s00256-0172767-6

\section{Wayne B. Cohen-Levy \\ Wayne.CohenLevy@jhsmiami.org}

Jean Jose

jjose@med.miami.edu

Andrew E. Rosenberg

ARosenberg@med.miami.edu

Juan Pretell-Mazzini

J.Pretell@med.miami.edu

1 Department of Orthopaedics, Jackson Memorial Hospital/University of Miami, PO Box 016960 (D27), Miami, FL 33101, USA

2 University of Miami, 1400 NW 12th AVE, Miami, FL 33136, USA

3 Department of Radiology - MSK and Sports Medicine Division, 1400 NW 12th AVE, Miami, FL 33136, USA

4 Department of Pathology, University of Miami Hospital, 1400 NW 12th AVE, Room 4060, Miami, FL 33136, USA

5 Department of Orthopaedics - Musculoskeletal Oncology, 1400 NW 12th AVE, Suite 4036, Miami, FL 33136, USA 
Fig. 1 a Ultrasound of the left shoulder mass. b-d MRI images of the left shoulder: (b) T1 weighted sagittal image, (c) T2 weighted fat suppressed axial image, (d) Post-contrast T2 weighted fat suppressed sagittal image
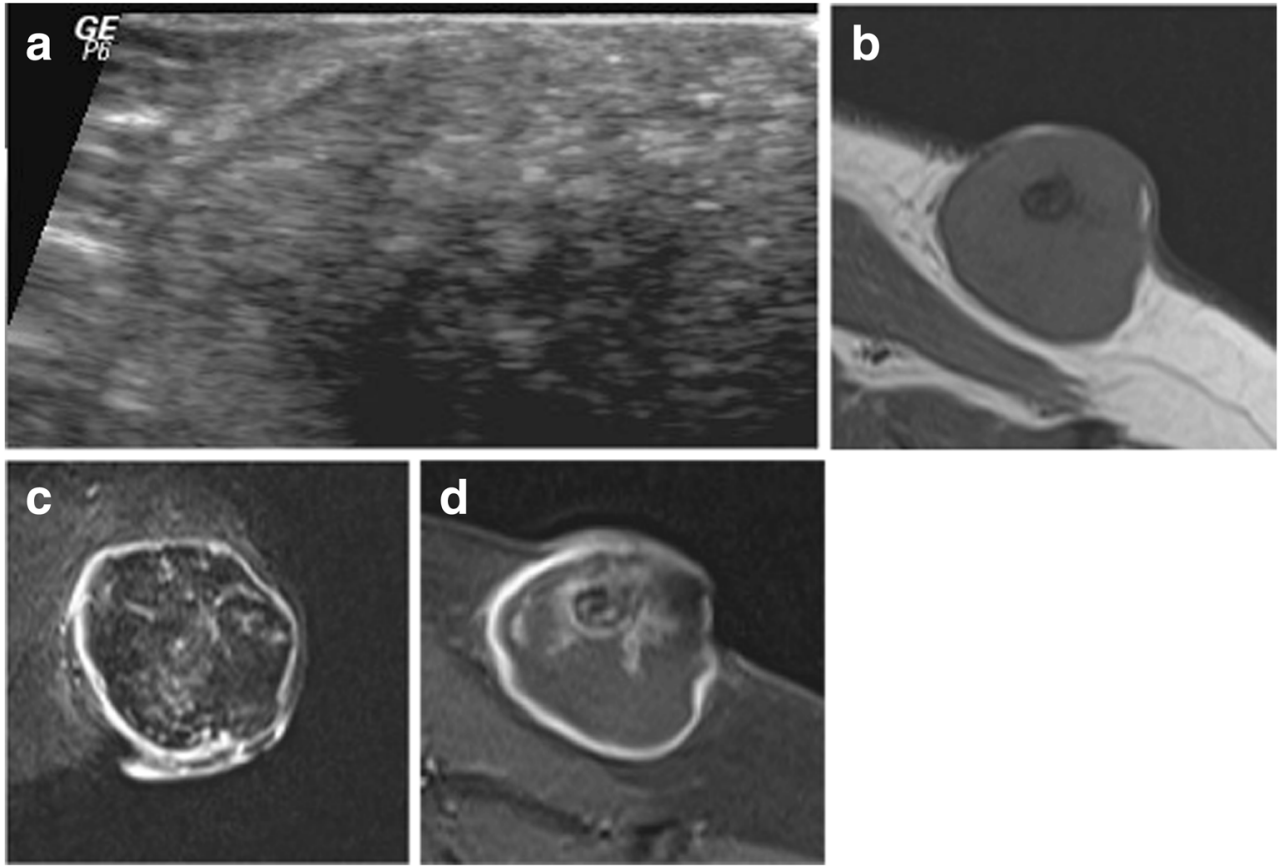
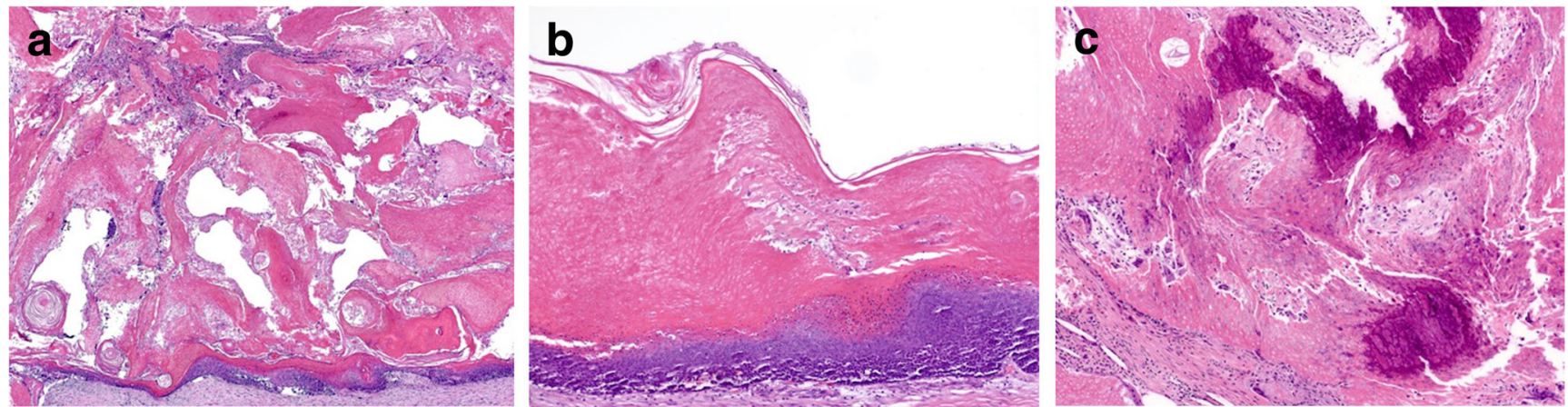

Fig. 2 a-c: Hematoxylin and eosin stain. a 2x Magnification, (b) 4x Magnification, (c) 10x Magnification

Funding information No funding was received from this research.

\section{Compliance with ethical standards}

Conflict of interest The authors declare that they have no conflict of interest. 